Editorial

\title{
Rapidly Changing Cities: Working with Socio-Ecological Systems to Facilitate Transformation
}

\author{
Karina Landman \\ Department of Town and Regional Planning, University of Pretoria, 0002 Pretoria, South Africa; \\ E-Mail: karina.landman@up.ac.za
}

Submitted: 3 May 2021 | Published: 25 May 2021

\begin{abstract}
Cities across the world are changing rapidly. Driven by population growth, migration, economic decline in rural areas, political instabilities, and even more recently, the Covid-19 pandemic, urban systems and spaces are changing to accommodate moving people and new functions. In many cases, these trends contribute to increased levels of inequality, poverty, food insecurity, and unemployment, while the warnings about the impact of climate change continue to raise concerns. Though some have called this a new urban revolution, others have referred to, in a more apocalyptic turn, the end of cities. In response, many writers are encouraging smarter cities, whereas others are promoting a post-urban context and a return to small communities. High levels of uncertainty are characteristic, along with increased intensities of complexity, rapid fluctuation and unbounded experimentation. This raises many questions about the nature and implication of change in different cities situated in vastly contrasting contexts. This thematic issue of Urban Planning focuses on five narratives from cities across the world to illustrate various drivers of change and their implications for urban design and planning. The editorial introduces these narratives, as well as commentaries from leading academics/practitioners and highlights several divergent experiences and common threats. It argues that to deal with the rapid and often large-scale changes, planners need to view human settlements as socio-ecological systems and plan for change and uncertainty to facilitate the co-evolution of humans and nature.
\end{abstract}

\section{Keywords}

complexity; rapidly changing cities; socio-ecological systems; sustainable development; urbanisation

\section{Issue}

This editorial is part of the issue "Planning for Rapid Change in Cities" edited by Karina Landman (University of Pretoria, South Africa).

(C) 2021 by the author; licensee Cogitatio (Lisbon, Portugal). This editorial is licensed under a Creative Commons Attribution 4.0 International License (CC BY).

\section{Introduction}

Cities across the world are changing rapidly. According to recent World Bank (2020) estimates, 55\% of the world's population live in cities and this is likely to increase to $70 \%$ by 2050 . The speed and scale of urbanisation give rise to many challenges such as the demand for affordable housing, well-connected transport systems, basic services, and jobs. At the same time, governments need to deal with rising conflicts and increasing numbers of displaced people living in urban areas. Yet, in addressing these needs, other problems are increased such as the over-use of scarce natural resources and increased vulnerabilities of the poor. Large-scale expansion on the urban periphery contributes to urban sprawl, while climate change risks increase the vulnerability of many coastal areas and informal settlements. Added to these is the challenge linked to combatting the Covid-19 pandemic, giving rise to simultaneous health, social, and economic crisis. This exposes how well cities are planned and managed or not, with the consequent implications on whether the city can cope and function (World Bank, 2020). This illustrates the complexity of interrelated factors that drive urban change in the world. Understanding how to plan for and manage change in complex systems is becoming more important than ever ( $\mathrm{Nel}$, du Plessis, 
\& Landman, 2018), especially in the context of multiple complexities in cities (Watson, 2003) and the presence of 'wicked problems,' which have no clearly defined problem or criteria for solution (Rittel \& Webber, 1973, p. 160). Considering cities as socio-ecological systems (SES) nested within the global SES offers a position from which the city can be studied as a problem of organised complexity (du Plessis, 2008).

This thematic issue of Urban Planning focuses on rapidly changing cities and seeks to interrogate the role of planning to accommodate new circumstances or situations emerging in cities across the world. How do we plan for uncertainty or deepening levels of complexity? How do planners encourage adaptation in different parts of human settlements within the limitations of strict rules and regulations? How does planning allow for evolutionary transitions demanded by a changing world? The purpose of this thematic issue is to rethink the planning and development of urban spaces and systems in terms of their contribution to a revised set of values, viewpoints, and mechanisms that may be needed to address rapid change in contemporary cities.

\section{Cities as SES}

Hes and du Plessis (2015) maintain that the current mechanistic worldview cannot adequately explain the present-day reality, especially as it relates to living systems; hence they advocate an ecological worldview. Such a worldview acknowledges that people are part of living systems and all that comes with such systems, such as flows, relationships, interdependence, and evolution. Everything that exists is part of a greater whole and the web of life (Hes \& du Plessis, 2015). This means that humans are not separate from nature but members of the web of life.

The Resilience Alliance (2010, p. 16) describes SES as complex, integrated systems in which humans are part of nature and ecosystems integrated with human society. Hes and du Plessis (2015, p. 27) say:

Social-ecological systems are far more than coupled human-nature systems in which humans rely on ecosystem services. Instead, social-ecological systems represent the combination of the 'exterior,' as created by biogeochemical processes and activities (in which humans and their technologies have come to play a disproportionate part), and the 'interior,' as created by, and experienced through, processes of thought and shared cultural phenomena.

Cities are also SES. The view of the city as a complex, adaptive socio-ecological system changes our perception of it as an artefact to that of the city and its various urban spaces as "an ever-changing sociospatial-temporal meta-process, comprising innumerable interacting and nested processes resulting from selforganisation and adaptation and resulting in the emer- gence of unpredictable patterns and events" (du Plessis, 2011 , p. 4). Working with change and uncertainty and looking for the potential inherent in specific places can enable an alignment between people and place to allow for the continuous co-evolution of humans and nature (Mang, Haggard, \& Regenesis, 2015). The increasing concerns about rapidly changing cities have opened up many questions related to the practices of transformation in cities to address various challenges and create better opportunities in the future.

\section{How Can We Deal with These Changes? Exploring Five Narratives and Years of Experience}

This thematic issue seeks to build on these discussions and broaden the views on how we can think about, and respond to rapidly changing cities. Specifically, we are interested in what happens in cities across the world or how they are changing and what this means for urban planning in the future. Through this endeavour, we hope to show that change does not have to be considered as only negative, but that while there are certain concerns, these may also open up opportunities for improvement at various levels.

The first narrative is situated in Japan and focuses on nature-based solutions to deal with rapid changes in urban environments. Roggema, Tillie, Keeffe, and Yan (2021) propose multiple responses and strategies to include nature in development processes towards more resilient and sustainable environments. The discussion highlights the importance of understanding various rates of change in specific parts of the city to apply multiple deployment strategies to ensure that rapid change include a focus on access to nature. It is argued that this would improve the quality of life and enrich ecological systems.

In the second story that focuses on China, Lam, Li, and $\mathrm{Yu}$ (2021) reconsider rapid change from a different angle by offering a counter approach to rapid urbanisation. The article proposes a two-fold strategy to assist rural development opportunities through physical and virtual connectivity, introducing the notion of digital ruralism. This would focus on, firstly, Transit-OrientatedDevelopment (TOD) to assist with access to health, governance, mobility, as well as environmental, social, economic, and human capital. The aim is thus to link human forces and commodities in rural areas. The second pillar focuses on Information \& Communication Technology (ICT) to access technology lifestyle and smart living opportunities. They point out that together TOD and ICT offer a mechanism to address most of Maslow's Hierarchy of needs.

Rapidly changing cities are often characterised by an increase in population and the need to address the climate change challenge through, for example, Blue-Green Solutions (BGS). However, rapid urbanisation and densification can also reduce the amount of green open space, especially in the form of play 
spaces for children. In the third narrative, Mottaghi, Kylin, Kopljar, and Sternudd (2021) acknowledge the relationship between humans and nature and show how the interaction between the natural environment and human behaviour affects different affordances in a park in Sweden. This is also influenced by the design of public spaces. The authors illustrate the co-benefits of multi-use for ecological values (BGS) and social values (play spaces for children) and advocate that planners and designers should give special attention to design and hierarchy to allow both these types of values to be addressed.

The next two articles shift the attention to major spatial transformation in two rapidly growing cities in the Global South. Rapid urbanisation creates a need for more housing and services, which often occurs on the urban periphery. The fourth story situated in Lahore, Pakistan, highlights three types of developments that are contributing to large-scale transformation. These developments were led by: 1 ) private developers; 2 ) the military; and 3) the government, respectively. They engulfed pre-existing villages and set in motion a process of resistance. Utilizing a framework of 'access-assemblages,' Cermeño (2021) shows how planning becomes an instrument in the hands of these powerful groups to legitimize exclusionary visions to the detriment of larger sections of the society. However, the discussion also shows that through a process of resistance, the territorialisation of land is often countered through de-territorialisation, setting in motion constant change through the emergence of re-/de-territorialisation.

The final narrative draws on military and enclave urbanism to highlight different ways of containment in Egypt. Ashoub and ElKhateeb (2021) point out that containment is used as a political tool for controlling the middle-class in Cairo. This does not only occur through typical fenced in gated communities built on the urban periphery in the desert but also through the containment of active citizens in the old city and neighbourhood of Heliopolis through new transport infrastructures such as bridges, fly-overs, and high-ways. In this way, the new infrastructure becomes a 'wall of roads' making it even harder for pedestrians and public transport users - by far the majority in the city-to move around in urban space. The authors argue that spatial interventions become a tool to constrain political freedom by disassociating citizens and undermining effective opposition through a limitation of public space and mobility.

The five narratives are complemented by two commentaries from planners with great experience in practice. The first commentary obliges us to pause for a moment and reflect on the many debates on changing urbanisation. It is a call to listen to lessons of wisdom from the past and adopting these to our future professional work. The think piece offers ten lessons from 55 years of experience and concludes that the ultimate goal of the work of built environment professionals should be to contribute to a better, more qualitative sus- tainable built environment. However, as pointed out, this is a never-ending process-always continuing in search of better actions and projects. Therefore, the discussion is a call for action, for hope to believe that despite worrying signs, things must and can change. Verschure (2021) argues that together with the power, spirit, and awareness of the younger generation, supported by the older generation, urban change can become an opportunity to change for the better.

The second commentary also focusses on the role of Planning to facilitate change to deliver better outcomes for all and questions whether Planning would still want to work towards change in rapidly expanding changings cities and whether it would be able to contribute to create something better. Drawing from the origins of Planning to highlight its transformational ability, it proceeds to suggest five considerations to ensure a constructive role in working with change. This would include understanding systemic connections in cities, highlighting that a failure to introduce transitions to address conditions threatening life and ecosystems on the planet threatens life everywhere. Responses should thus be aligned to current challenges and use these crises to push for systemic and structural change to bring about a new system. Similarly, to the first commentary, it is a call for action, for planners to continue dreaming and, therefore, Oranje (2021) concludes with a message to planners to do what has to be done in the world to bring about positive change.

\section{Conclusion: Working with SES and the Role of Planning}

This thematic issue presents seven divergent accounts and a reflection of attempts to understand the rapid changes and responses to these in multi-cultural societies and different contexts. While some of these stories focus more on the findings of research projects or observations of changes occurring in space, others are geared more too specific interventions related to the improvement of cities and public space. However, there are also several common threats present in these accounts, including: 1) a need to reconnect to nature or consider both social and ecological values; 2 ) to acknowledge that change is an ongoing process; and 3 ) to be able to deal with increased socio-spatial complexities emerging from the interaction between humans and their environment in various contexts.

What is evident, though, is that rapidly changing cities does not necessarily mean the end of cities, but may offer a new opportunity to utilize change for the better. It does not imply an urban revolution, but rather an evolution towards a more healing and thriving environment (Landman, 2019). For this to materialize, there is a need to consider cities as an integrated socio-ecological system in which humans are part of nature and ecosystems integrated within society. A view of cities as SES will allow urban planners to work with complex systems 
nested in cities and therefore to use change and various forms of domination and resistance to open up greater opportunities for all people. Urban planners, therefore, need to view human settlements as a socio-ecological system and plan for change and uncertainty to facilitate the co-evolution of humans and nature.

\section{Conflict of Interests}

The author declares no conflict of interests.

\section{References}

Ashoub, S. H., \& ElKhateeb, M. W. (2021). Enclaving the city; New models of containing the urban populations: A case study of Cairo. Urban Planning, 6(2), 202-217.

Cermeño, H. (2021). Living and planning on the edge: Unravelling conflict and claim-making in peri-urban Lahore, Pakistan. Urban Planning, 6(2), 189-201.

du Plessis, C. (2008). Understanding cities as socialecological systems. Paper presented at the World Sustainable Building Conference, Melbourne, Australia.

du Plessis, C. (2011). Complexity, resilience, regeneration: New directions for sustainable human settlements. In Proceedings of the Annual Research Conference, South African Council for the Quantity Surveying Profession (pp. 1-11). Midrand: South African Council for the Quantity Surveying Profession.

Hes, D., \& du Plessis, C. (2015). Designing for hope: Pathways to regenerative sustainability. London: Routledge.

Lam, S., Li, H., \& Yu, A. T. W. (2021). A demand-side approach for linking the past to future urban-rural development. Urban Planning, 6(2), 162-174.

Landman, K. (2019). Evolving public space in South Africa: Towards regenerative space in the post-apartheid city. London: Routledge.

Mang, P., Haggart, B., \& Regenesis. (2014). Regenerative development and design: A framework for evolving sustainability. Hoboken, NJ: John Wiley \& Sons.

Mottaghi, M., Kylin, M., Kopljar, S., \& Sternudd, S. (2021). Blue-green playscapes: Exploring children's places in stormwater spaces in Augustenborg, Malmö. Urban Planning, 6(2), 175-188.

Nel, D., du Plessis, C., \& Landman, K. (2018). Planning for dynamic cities: Introducing a framework to understand urban change from a complex adaptive systems approach. International Planning Studies, 22(3), 250-263.

Oranje, M. (2021). Challenging times and planning: Origins, endings, and new beginnings? Urban Planning, 6(2), 225-227.

Resilience Alliance. (2010). Assessing resilience in social-ecological systems: Workbook for practitioners (Revised version 2.0). Atlanta, GA: Resilience Alliance. Retrieved from https://www.resalliance. org/files/ResilienceAssessmentV2_2.pdf

Rittel, H. W. J., \& Webber, M. M. (1973). Dilemmas in a general theory of planning. Policy Sciences, 4(2), 155-169.

Roggema, R., Tillie, N., Keeffe, G., \& Yan, W. (2021). Nature-based deployment strategies for multiple paces of change: The case of Oimachi, Japan. Urban Planning, 6(2), 143-161.

Verschure, H. (2021). Lessons learned from 55 (or more) years of professional experience in urban planning and development. Urban Planning, 6(2), 218-224.

Watson, V. (2003). Conflicting rationalities: Implications for planning theory and ethics. Planning Theory and Practice, 4(4), 395-407.

World Bank. (2020). Urban development. World Bank. Retrieved from https://www.worldbank.org/en/ topic/urbandevelopment/overview

\section{About the Author}

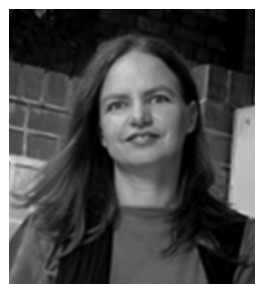

Karina Landman is an Associate Professor at the University of Pretoria, South Africa, and has a background in Architecture, Urban Design, and Planning, with a PhD in Urban Design. Her research areas include crime prevention through environmental design, gated communities, sustainable development, including resilient and regenerative cities, and public space. She has published widely on these issues, including a book entitled Evolving Public Space in South Africa (2019). 